\title{
Assessing Physical Activity among Canadian Healthcare Professionals
}

QR CODE

口fritg

\section{RAVNEET SANDHU*1, GURNOOR KAUR PANNU²}

INTRODUCTION: Physical Activity is well known to keep illness at bay and promote healthy living among people. In today's fast paced life, obesity is increasing amongst people and this can be eliminated through proper physical activity.

AIM: To assess the physical activity among various Canadian healthcare professionals.

MATERIALS AND METHOD: The present study was a multi-institution based observational study using a pre-tested, pre-validated questionnaire distributed among various colleges and privately practicing healthcare professionals in Canada using a close-ended questionnaire divided into five sections and containing 28 questions. Data analysis was done using SPPS version 19.0 and the independent samples t-test and multiple logistic regression was applied. Data was only considered significant when p was less than or equal to 0.05 .

RESULTS: Most males belonged to the "overweight" category (56.3\%), while females belonged to the "normal" category (56.3\%). A lesser number of females reported being obese $(5.4 \%)$ as compared to their male counterparts; significant difference ( $\mathrm{p}=0.05)$ was observed between males and females in the underweight category. Males were found to be insufficiently active (41.8\%), while $44.8 \%$ females were found to be in the active category. Statistical differences were observed while comparing the physical activity levels between the males and females belonging to the Insufficiently Active category $(\mathrm{p}=0.02)$.

CONCLUSION: Healthcare professionals should be reminded regarding their general health and the role of physical exercise in keeping them healthy.

KEYWORDS: Physical Activity, Obesity, Body Mass Index (BMI)

\section{INTRODUCTION}

Today's health professionals follow a very busy schedule, which ranges from academics and/or patient work to spending time with their family. Sometimes they have some other additional responsibilities too, which leaves very less time for them to pursue any kind of physical activity.

A lack of exercise often leads to one being obese and one of the best tool to fight obesity is through regular physical activity, defined as "any force exerted by muscles that results in energy expenditure above resting level". ${ }^{1}$ The entire globe is facing an epidemic of noncommunicable diseases (NCDs) and none or little physical activity is a significant contributing factor towards the development of such diseases.

The Centers for Disease Control (CDC) recommends at least 30 min of moderate intensity physical activity for at least 5 days per week for adults (i.e., $150 \mathrm{~min}$ of moderate intensity physical activity per week). ${ }^{2,3}$ Epidemiological research has proven that 15 to $20 \%$ of the overall risk for coronary heart disease, type 2 diabetes, colon cancer, breast cancer, musculoskeletal diseases, and psychological disorders is attributable to physical inactivity. ${ }^{4}$ Studies have also reported that atleast $60 \%$ of the world's population fails to complete the recommended amount of physical activity required to induce health benefits. ${ }^{5}$

Healthcare professionals focus their efforts on providing care for their patients without worrying about their well-being. Sedentary work, which their profession demands, causes repeated strain in muscles, tendons, and other body tissues, which could lead to the development of musculoskeletal disorders, further restricting their ability to perform any kind of physical activity.

Hence, it is important that healthcare professionals are always involved in some kind of physical activity throughout their life to increase and maintain their musculoskeletal health. ${ }^{6,7}$

Such is the importance of physical health that it cannot be avoided by the healthcare professionals. Hence, this study was conducted to assess the physical activity 
among various Canadian healthcare professionals.

\section{MATERIAL AND METHODS}

Study area and study population: The present study was a multi-institution based observational study using a pre-tested, pre-validated questionnaire distributed among various colleges and privately practicing healthcare professionals in Canada. They were contacted online or personally by the team of investigators to fill the questionnaire after explaining them about the aim and objectives of the study. Participation in the study was purely voluntary and data was coded to assure confidentiality of data. Prior to commencement of the study, all necessary approvals (including ethical clearance) and permissions were duly taken.

Sample size: The study adopted a convenience sampling approach and targeted the maximum number of healthcare professionals as possible.

Data Collection Instrument: Data was collected using a close-ended questionnaire divided into five sections and containing 28 questions. The questionnaire was adopted and modified from Anand $\mathrm{T}$ et al. ${ }^{8}$ The Cronbach's Alpha $(\alpha)$ was found to be 0.79 . A pilot study on 25 people was done to determine the feasibility of the study; and those results were not included in the final analysis.

The healthcare professionals were asked to provide selfreported values of height and weight from which BMI was calculated. The questionnaire contained six questions about their participation in moderate or vigorous physical activity during a typical week including the days and duration of involvement in physical activity. Consistent with the guidelines by CDC, ${ }^{3}$ three groups were defined. Respondents who reported no physical activity (i.e., inactive) were assigned to physical activity level I; participants who reported the physical activity that was less than the recommended level but greater than none (i.e., insufficient) were assigned to physical activity level II; and those who reported moderate physical activity for at least 30 min per day on at least 5 days per week or vigorous physical activity for at least 20 min per day on at least 3 days per week (i.e., recommended level) were assigned to physical activity level III.

Statistical analysis: Data was handled by the principal investigator and entered into Microsoft Excel, which was coded before being sent to a statistician for analysis. Data analysis was done using SPPS version 19.0 and the independent samples t-test and multiple logistic regression was applied. Data was only considered significant when $\mathrm{p}$ was less than or equal to 0.05 .

\section{RESULTS}

A total of 576 questionnaires were distributed, out of which, only 451 could be included in the study as the rest were either not returned or had incomplete responses. The response rate was hence, $78.3 \%$.

There were $222(49.2 \%)$ males and $229(50.8 \%)$ females who participated in the study. The mean BMI of the study participants is depicted in table 1 . It was observed that most males belonged to the "overweight" category (56.3\%), while females belonged to the "normal" category $(56.3 \%)$. A lesser number of females reported being obese $(5.4 \%)$ as compared to their male counterparts. A significant difference $(\mathrm{p}=0.05)$ was observed between males and females in the underweight category.

\begin{tabular}{|c|c|c|c|c|}
\hline & Males & Females & Total & $\begin{array}{c}\mathbf{p} \\
\text { value } \\
\text { (from } \\
\text { t- } \\
\text { test) }\end{array}$ \\
\hline $\begin{array}{l}\text { Underweight } \\
\qquad(\leq 18.4)\end{array}$ & $26(11.7 \%)$ & $59(25.7 \%)$ & $\begin{array}{c}85 \\
(18.8 \%)\end{array}$ & $0.05^{*}$ \\
\hline $\begin{array}{c}\text { Normal } \\
(18.5-22.9)\end{array}$ & $25(11.2 \%)$ & $129(56.3 \%)$ & $154(34.1 \%)$ & NS \\
\hline $\begin{array}{c}\text { Overweight } \\
(23-24 \cdot 9)\end{array}$ & $125(56.3 \%)$ & $29(12.6 \%)$ & $\begin{array}{c}154 \\
(34.1 \%)\end{array}$ & NS \\
\hline Obese $(\geq 25)$ & $46(20.8 \%)$ & $12(5 \cdot 4 \%)$ & $58(13 \%)$ & NS \\
\hline Total & $222(49.2 \%)$ & $229(50.8 \%)$ & $451(100 \%)$ & NA \\
\hline Table 1. B & $\begin{array}{l}\text { the stuc } \\
\text { NA: }\end{array}$ & . & Non-Si & ant, \\
\hline
\end{tabular}

The physical activity levels of the study population is depicted in table 2 . Most males were found to be insufficiently active (41.8\%), while $44.8 \%$ females were found to be in the active category. Statistical differences were observed while comparing the physical activity levels between the Insufficiently Active category between males and females $(\mathrm{p}=\mathbf{0 . 0 2})$.

\section{DISCUSSION}

The present study, which aimed to assess the Knowledge, Attitude and Physical Activity Levels among various healthcare professionals revealed that 
most of them belonged to the normal (34.1\%) and overweight (34.1\%) category. Mostly, males were found to be overweight $(56.3 \%)$ and females were found to be in the normal range of BMI (56.3\%). The results are higher as compared to Singh A et al. ${ }^{9}$ who reported that dental faculty were either "overweight" or "obese". Thakar S et al. ${ }^{10}$ who also conducted their study among dental professionals, revealed an almost equal number of normal (32.9\%), overweight (27.3\%) and obese $(35.2 \%)$ dental professionals.

\begin{tabular}{|c|c|c|c|c|}
\hline \multicolumn{1}{c}{$\begin{array}{c}\text { Physical } \\
\text { Activity Level }\end{array}$} & Males & Females & Total & $\begin{array}{c}\text { p- } \\
\text { value } \\
\text { (MLR) }\end{array}$ \\
\hline Inactive (I) & $86(38.7 \%)$ & $41(17.9 \%)$ & $\begin{array}{c}127 \\
(28.2 \%)\end{array}$ & NS \\
\hline $\begin{array}{c}\text { Insufficiently } \\
\text { Active (II) }\end{array}$ & $93(41.8 \%)$ & $85(37.1 \%)$ & $\begin{array}{c}178 \\
(39.5 \%)\end{array}$ & $\mathbf{0 . 0 2}^{*}$ \\
\hline Active (III) & $43(19.5 \%)$ & $\begin{array}{c}103 \\
(44.9 \%)\end{array}$ & $\begin{array}{c}146 \\
(32.3 \%)\end{array}$ & NS \\
\hline Total & $\mathbf{2 2 2}(49.2 \%)$ & $\mathbf{2 2 9}(50.8 \%)$ & $\begin{array}{c}451 \\
(100 \%)\end{array}$ & NA \\
\hline
\end{tabular}

Table 2. Physical Activity levels of the study population. (NS: Non-Significant, NA: Not Applicable, MLR: Multiple Logistic Regression)

In disagreement to these results, Suija et al. ${ }^{11}$ reported no statistically significant relationship between the level of physical activity and general characteristics (age, living area, BMI, time spent sitting) among 198 Estonian family doctors, respectively. Lobelo et al. concluded that there is a need among medical schools need to increase the proportion of students adopting and maintaining regular physical activity so as to significantly increase the quality of future physical activity counselling being delivered by doctors. ${ }^{12}$

Most of the healthcare professionals in the present study reported being Insufficiently active (39.5\%), and a majority of males (41.8\%) being insufficiently active while most females (44.9\%) reported being in the active category. The results are in agreement to Anand T et al. ${ }^{8}$ (47.2\% Insufficiently active study population) and Han MA et al. (33.1\%, Korean Population). ${ }^{13}$

Such increased BMI percentages and physical activity from the normal levels are of particular concern and specially among developing nations as these great nation are undergoing an epidemiological change, as a result of which, non-communicable diseases are becoming the leading cause of deaths in the community and physical activity is an important tool in the in the fight against obesity/increased BMI values. ${ }^{14}$ The main reasons for such decreased physical activity may be due to the working hours of the clinics, which mostly operate in the evenings as it is convenient for the working population to visit them. A few healthcare professionals also work in colleges during the day and then continue with their private practice in the evening, which leave them no time to focus of self-care.

\section{CONCLUSION}

Based on the results of the current study, it is advised that healthcare professionals be regularly reminded regarding the benefits and they should be encouraged to pursue more physical activity on a daily basis.

\section{REFERENCES}

1. Caspersen CJ, Powell KE, Christensen GM. Physical activity, exercise, and physical fitness: definitions and distinctions for health-related research. Public Health Rep. 1985;100:126-31.

2.Mokdad AH, Giles WH, Bowman BA, Mensah GA, Ford ES, Smith SM, et al. Changes in health behaviors among older Americans, 1990 to 2000. Public Health Rep 2004;119:356-61.

3. Pate RR, Prate M, Blair SN, Haskell WL, Macera CA, Bouchard C, et al. Physical activity and public health. A recommendation from the Centers for Disease Control and Prevention and the American college of Sports Medicine. JAMA 1995;273:402-7.

4. Bauman A, Miller Y. The public health potential of health enhancing physical activity. In: Oja P, Borms J, eds. Health-enhancing physical activity. International Council of Sport Science and Physical Education; 2004. 5. WHO. The World Health Report 2004-changing history. Geneva: WHO; 2004.

6. Brill P, Macera CA, Davis DR, Blair SN, Gordon N. Muscular strength and physical function. Med Sci Sports Exerc. 2000;32:412-416.

7. Sallis JF, Hovell MF, Hofstetter CR, Faucher P, Elder $\mathrm{JP}$, Blanchard $\mathrm{J}$, et al. A multivariate study of determinants of vigorous exercise in a community sample. Prev Med 1989;18:20-34.

8. Anand T, Tanwar S, Kumar R, Meena GS, Ingle GK. Knowledge, attitude, and level of physical activity among medical undergraduate students in Delhi. Indian J Med Sci. 2011;65:133-42.

9. Singh A, Purohit B. Physical Activity, Sedentary Lifestyle, and Obesity Among Indian Dental Professionals. Journal of Physical Activity and Health, 2012, 9, 563-570

10. Thakar S, Shivlingesh KK, Jayaprakash K, Gupta B, Gupta N, Anand R, et al. High Levels of Physical Inactivity Amongst Dental Professionals: A 
Questionnaire Based Cross Sectional Study. J Clin Diagn Res. 2015;9(1):ZC43-ZC46. https://doi.org/10.786o/JCDR/2015/10459.5466

11. Suija K, Pechter U, Maaroos J, et al. Physical activity of Estonian family doctors and their counselling for a healthy lifestyle: a cross-sectional study. BMC Fam Pract. 2010;11:48.

12. Lobelo F, Duperly J, Frank E. Physical activity habits of doctors and medical students influence their counselling practices. Br J Sports Med. 2009;43:89-92.
13. Han MA, Kim KS, Park J, Kang MG, Ryu SY. Association between levels of physical activity and poor self-rated health in Korean adults: The Third Korea National Health and Nutrition Examination Survey (KNHANES), 2005. Public Health 2009;123:665-9.

14. Joshi R, Magnolia Cardona M, Iyengar S, Sukumar A, Raju CR, Raju KR, et al. Chronic diseases now a leading cause of death in rural India-mortality data from the Andhra Pradesh Rural Health Initiative. Int J Epidemiol. 2006;35(6):1522-29.

Source of support: Nil, Conflict of interest: None declared

Cite this article as:

Sandhu R, Pannu GK. Assessing Physical Activity among Canadian Healthcare Professionals. Int Healthc Res J. 2020;4(3):69-72. https://doi.org/10.26440/IHRJ/0403.06351

\section{AUTHOR AFFILIATIONS: ( ${ }^{*}$ Corresponding Author)} 1. Dental Consultant, Ontario, Canada-L7 $\mathrm{C}_{3} \mathrm{~W}_{7}$. 2. Associate Dentist, Lake Barrington, Illinois, USA.
Corresponding Address:

Dr. Ravneet Sandhu

6 Jamestown Crt

Caledon, Ontario

Canada-L7C3W7
Contact corresponding author at: ravneetsandhuzo94[at]gmail[dot]com 